Psychological Topics, 30 (2021), 1, 31-56

Original Scientific Paper

UDC: 159.922 .1 .072

316.474

$316: 613.88$

https://doi.org/10.31820/pt.30.1.2

$613.88: 316$

\title{
Blue-Eyed Men Prefer Blue-Eyed Women: The Role of Life History Strategies and Sociosexuality
}

\author{
Asmir Gračanin, Kevin Kutnjak, and Igor Kardum \\ University of Rijeka, Faculty of Humanities and Social Sciences, \\ Department of Psychology, Rijeka, Croatia
}

\begin{abstract}
Previous research (Laeng et al., 2007) conducted on Norwegian samples showed that blue-eyed men rate blue-eyed women as more attractive, while brown-eyed men and all the women show no differences in attractiveness assessments with respect to eye colour. Correspondingly, positive assortative mating was found for blue, but not brown eyes, and it most often occurred in blue-eyed men. We aimed to replicate this blue-like-blue effect in the Croatian population, which differs in the ratio of eye colour phenotypes (blue eye colour is the most prevalent in Norway while brown is the most prevalent in Croatia). Additionally, we examined whether this effect is moderated by life history strategies and sociosexuality. Our hypothesis was that the effect would be larger in those blue-eyed men who exert a slower life history strategy and who are sociosexually restrictive. One hundred and twenty-eight participants assessed the attractiveness of blue-eyed and brown-eyed models, whose eye colours were experimentally manipulated in such a way that participants were shown models with natural or artificially changed eye colours. The blue-like-blue effect was replicated in the context of preferences, although it was smaller than in the original study. However, unlike the original study, in a sample of 138 participants no assortative pairing by eye colour was found between participants and their romantic partners. Finally, the hypothesis about the moderation was supported for life history strategies, but not for sociosexuality. In addition to the rationale for the blue-like-blue effect based on the paternity uncertainty account, which was offered by the authors of the original study, we discussed other accounts of this phenomenon.
\end{abstract}

Keywords: eye colour, assortative mating, paternity uncertainty, life history strategies, sociosexuality

\section{Introduction}

Numerous studies show that people find others more attractive if they are similar to themselves in a number of characteristics, including demographic variables

Asmir Gračanin, Department of Psychology, Faculty of Humanities and Social Sciences, University of Rijeka, Sveučilišna avenija 4, 51000 Rijeka, Croatia. E-mail: agracanin@ffri.hr

This work has been fully supported by the University of Rijeka under the project number uniri-drustv-18-231. 
such as age, race, and education, psychological variables, such as various attitudes, personality, and intelligence, and also physical traits, such as height or general attractiveness (see a review by Luo, 2017). While these similarity preferences for certain characteristics of the opposite sex individuals do not always translate into actual relationship formation, it is nevertheless more likely that romantic relationships would be formed between more similar people. This phenomenon, termed positive assortative mating (AM) or homogamy, has been extensively studied and has been observed for a number of features, including those listed above (e.g., Youyou et al., 2017). Despite these general trends, the degree of similarity preferences and AM is variable across different characteristics and across different individuals and couples. In the current paper we focus on the similarity preferences for eye colour in dependence on one's own eye colour as well as AM in this facial feature. Additionally, we explored whether mating-related personality traits affect eye colour similarity preferences.

Laeng et al. (2007) examined the preference for blue or brown eye colour depending on the eye colour of the assessor, by asking study participants to rate attractiveness of depicted models. Their study also explored the relationship between participants and their romantic partners' eye colour. The main premise of the study was based on the possibility that the blue eye colour in humans reflects a simple, predictable, and reliable cue to inheritance, since for blue eyes there is always direct concordance between the genotype and phenotype (Laeng et al., 2007). In order for the blue-eye phenotype to occur, an individual must inherit two recessive blue-eye alleles: one from the mother and one from the father (Sturm \& Frudakis, 2004). On the other hand, heterozygous brown-eyed individuals carry an allele that is not concordant with the observed eye colour. Therefore, only in blue-eyed men, eye colour provides a visible and salient cue to the child's heredity. If a blue-eyed man mates with a blue-eyed woman and a non-blue-eyed child is born, the man can be certain that he is not the father. Laeng et al. (2007) hypothesized that, if men generally choose women with characteristics that promote the assurance of paternity (Schmitt, 2014), blue-eyed men should feel more attracted to and prefer blue-eyed women, which represents a male adaptation for the detection of extra-pair paternity. A consequence of such preferences should also be evident in the positive AM in eye colour, especially when it comes to blue-eyed males. Since paternal uncertainty for brown-eyed men is not affected by the eye colour of their partners, no preferences for female eye colour are expected. Also, since maternal uncertainty is not an issue, no preferences for male eye colour are expected (Laeng et al., 2007). The results of their two studies performed on Norwegian samples confirmed both the preference and the assortment hypothesis. The first goal of the current research is to try to replicate this blue-like-blue effect.

Blue eyes are the result of a mutation that decreases the pigmentation of the iris, which appeared in a common European ancestor (Sturm \& Frudakis, 2004). The genes coding for blue eyes seem to have been selected because of their joint effects 
on eyes, hair, and skin pigmentation, which provided certain adaptive advantages related to exposure to light and specific diet in high latitudes, as well as in the context of frequency-dependent sexual selection (Wilde et al., 2014). Laeng et al. (2007) conducted their studies on a Norwegian sample, where 55\% of participants were blue-eyed and only $15.9 \%$ brown-eyed. The exact ratio of these eye colours in the Croatian population is unknown, but it is evident that most Croatians are browneyed, with blue- and green-eyed phenotypes being rarer. Correspondingly, the blueeyed phenotype in Central and South Europe is a minority, but still of significant size (Beals \& Hoijer, 1965). For example, Zanetti et al. (1996) examined a sample of 1800 Italians and concluded that the blue-eyed phenotype makes up approximately $24 \%$ of the population. Though these findings are relatively old, they can be used as a basis for approximation of the eye colour phenotypes in neighbouring Croatia. The brown-eyed phenotype probably makes up more than $50 \%$ of the population and the blue-eyed phenotype around $25 \%$. This ratio may have important implications for the current study. Specifically, Laeng et al. (2007) hypothesized that the effect observed in their study should be even greater in populations where the blue-eye phenotype is a minority. Namely, the more common the blue-eyed phenotype is in the population, the less reliable a cue for paternity the child's blue eyes become, since there is a higher chance the lover (and biological father of the child) is also blueeyed. Therefore, if paternity certainty assurance is a mechanism behind the blue-likeblue effect, then this effect should be larger in Croatian than in the Scandinavian sample.

A first alternative to the evolutionary-based explanation of the blue-like-blue effect is one that is based on a cultural mechanism (Laeng et al., 2007). Preference for blue-eyed women in blue-eyed men could be the result of prejudice and stereotypes towards ethnically non-Scandinavian (often brown-eyed) people, rather than of selective pressure. However, the authors dismiss such a possibility due to the fact that the blue-eyed phenotype dominated both the Scandinavian population and the largest immigration groups into Norway. Specifically, at the time these studies were conducted, the majority of the immigration was from Northern Europe, North America and Eastern Europe (Forgaard \& Dzamarjia, 2004). Moreover, if the preference for blue-eyes were a mechanism of discerning Scandinavians from nonScandinavians then brown-eyed Scandinavian men, as well as women (regardless of eye colour) should also prefer blue-eyes, which was not supported by the studies' results (Laeng et al., 2007). Finally, in some North-European countries, there is a prevalence of the belief that blue eyes are more attractive than eyes of other colours, while at the same time there are no differences found when it comes to the expression of preferences for eye colour directly, i.e., by rating attractiveness of presented individuals (Gründl et al., 2012). Nevertheless, this prejudice itself also cannot explain the preferences that are limited to blue-eyed men only.

Laeng et al. (2007) based their hypothesis solely on their carefully elaborated specific adaptationist account of the blue-like-blue effect. However, there are other 
potentially valid biological and psychological explanations of their findings. First, the genes coding for eye colour and other related physical features, such as skin and hair pigmentation (Jablonski, 2018), seem to show pleiotropic effects by also coding for certain more global traits that might, because of any reason, affect eye colour preferences. Rather than necessarily representing a response based on some evolved adaptive mechanism, these preferences, while still being systematic, could be caused by certain psychological mechanisms that have nothing to do with adaptive behaviour, at least not in the specific paternity uncertainty context. For example, blue-eyed infants and children seem to be characterized by a group of inter-related psychological features, such as higher behavioural inhibition (Rosenberg \& Kagan, 1987, 1989), social wariness (Coplan et al., 1998), high reactivity, and shyness (Kagan \& Snidman, 2004). Interestingly, brown-eyed men but not women were found to be perceived as more dominant (Kleisner et al., 2010), but also more trustworthy (Kleisner et al., 2013). While it is impossible to pinpoint a specific mechanism through which such personality features might affect the opposite sex eye-colour preferences, the possible links would certainly be based on a complex interplay between several factors. For example, certain personality features might simply influence the amount of attention that an individual typically directs towards the eyes of other people (Gutiérrez-García et al., 2019), which, in turn, could facilitate the otherwise existing effects of positive stereotypes towards blue eyes (Gründl et al., 2012). Next, positive sexual imprinting (preferences for mates with characteristics that correspond to the opposite sex parent as a consequence of developmental exposure) is documented across different animal species (e.g., Kendrick et al., 1999) and humans (Bereczkei et al., 2002), even in the context of eye-colour preferences (Bressan, 2020). Sexual imprinting might not be a general process strong enough to cause the observed effect of blue-eyes preferences, as shown by Laeng et al. (2007). It might also seem to be an unlikely explanation of the current phenomenon due to the (clearly counterintuitive) fact that brown-eyed, rather than blue-eyed individuals have a slightly greater likelihood of having the samecoloured-eyes parents, which should make them, rather than blue-eyed ones, show higher preferences for partners with the same eye colour. Nevertheless, the effects of sexual imprinting, when combined with the above mentioned distinctive personality features of blue-eyed individuals, might also represent a plausible explanation of the blue-like-blue effect. Finally, specific personality features such as high reactivity or behavioural inhibition of blue-eyed individuals might facilitate preferences towards more familiar stimuli, such as the colour of one's own eyes (see Nojo et al., 2012). Any of these effects could be expected to work primarily in (blue-eyed) men, who, in contrast to women, tend to base romantic partner choice largely on physical attractiveness rather than on personal characteristics that promote parental investment (Simpson \& Gangestad, 1991). Thus, while our aim is to replicate the original study that found the blue-like-blue effect in the context of mate preferences and positive assortment, we do not adhere to any single explanation of that effect. 
The next interesting question is whether the blue-like-blue effect shows any systematic variability in relation to some important individual differences. Since the initial rationale for the blue-like-blue effect came from theorizing about reproductive adaptations, it would make sense to turn our attention to those aspects of personality variables that are relevant for that context as well. Key factors that might affect preferences towards physical characteristics similar to one's own (and consequently, AM in these traits) are life history strategies (LHS). According to Life History Theory, an individual can strategically allocate energy and material resources among different components of fitness (Stearns, 1976). For example, calories and nutrients can be invested into growth vs reproduction. Since resources are limited and high investment in both of these aspects of life is impossible, trade-offs occur (Figueredo et al., 2006). The extremes on this continuum are traditionally called $r$ ("fast") and $K$ ("slow") reproductive strategies. The $K$ strategy implies a larger investment in one's own growth and development as well as the production of a smaller number of higherquality offspring, which consequently have a better chance of survival and further reproduction. On the other hand, $r$ strategy is based on rapid reproductive maturation, production of more offspring, and low parental investment, with offspring having a lower chance of survival and reproduction (Stearns, 1976). Humans appear to be highly K-selected, as evident from slow sexual development, production of only one to two offspring at a time, and relatively low infant mortality rates due to substantial parental investment (Figueredo et al., 2006). However, a substantial degree of interindividual variation in human life history strategies has been demonstrated, so that when applied to humans, Life History Theory is often referred to as "Differential $K$ " Theory (Giosan 2006; Rushton 1985). High K (or slow LHS) strategy in humans includes long-term thinking and planning for the future, commitment to long-term romantic relationships, extensive parental investment, building social support structures, adherence to interpersonal rules (e.g., altruism and cooperation), and careful consideration of risk before taking action (Figueredo et al., 2006).

A construct closely related to LHS is sociosexuality. Simpson and Gangestad (1991) define sociosexuality as a personality dimension, with the ends of this continuum denoting two different strategies: restrictive and non-restrictive. Sociosexually restricted individuals prefer more emotional attachment and intimacy with a partner before engaging in sexual intercourse. They also prefer more loyal, kind, and responsible partners ready for long-term investment and correspondingly they have a smaller number of longer lasting relationships. Unrestricted individuals are more prone to sexual intercourse in the earlier stages of a romantic relationship and are more often sexually active with multiple partners in the same period. Their relationships are characterized by low attachment and more generally, by low investment (Penke \& Asendorpf, 2008; Simpson \& Gangestad, 1991). Restricted sociosexual orientation can be viewed as a psychosocial reflection of a slower reproductive strategy which favours quality over the quantity of offspring, while unrestricted orientation corresponds to a faster reproductive strategy which favours 
quantity over the quality of offspring (Penke \& Asendorpf, 2008; Rushton, 1985; Simpson \& Gangestad, 1991).

From the perspective of the paternity uncertainty account, if men with recessive phenotypes (like blue eyes) find more attractive and prefer as partners women with the same characteristic, it may be assumed that these preferences are more pronounced in men that are characterized by the slower, High K reproductive strategy or are more sociosexually restrictive. Because they apply a strategy in which parental investment is higher, potential cuckoldry would be more detrimental to their reproductive success. On the other hand, men who apply a faster, low $K$ reproductive strategy or are sociosexually unrestrictive should pay less attention to their partner's eye colour, as they apply a strategy in which parental investment is low or nonexistent, implying that potential cuckoldry is less costly. More specifically, we predict that the effects on the eye colour preferences observed by Laeng et al. (2007) should be greater in blue-eyed men who apply slower life history strategies or are more restrictive than in those who apply faster life history strategies or are less restrictive.

According to Figueredo and Wolf (2009), positive assortment is more common in people who apply slower, than those who apply faster reproductive strategies. Faster reproductive strategies are favoured in unpredictable, unstable and uncontrollable environments. In such conditions genetic diversification of offspring is favoured because it increases the likelihood of survival of at least some offspring. On the other hand, stable and predictable environmental conditions favor slower reproductive strategies and lower genetic diversification as a means of preserving well-adapted phenotypes. Thus, homogamy should be more likely to occur in high $\mathrm{K}$ individuals (Figueredo \& Wolf, 2009). This was recently supported by research on the assortment of some basic personality traits (Gračanin et al., 2018). Also, when it comes to preferences, self-resemblance in facial characteristics was found to decrease attractiveness of potential mates in a short term but not in the long term mating context (DeBruine, 2005), with the latter being closer to the application of $\mathrm{K}$ strategy. Thus, the pursuit of homogamy, in both expressing the preferences and forming romantic relationships, might represent a more acceptable strategy for slow $\mathrm{K}$ individuals. However, this still does not explain why homogamy (or preferences for similar traits) should be more pronounced in high $\mathrm{K}$ individuals only in case of blue-eyed men. We assume that these homogamy preferences in high $\mathrm{K}$ individuals could be potentiated by some random factors, stemming from the above mentioned pleiotropic effects of genes coding for blue eyes.

Finally, both the rationale based on homogamy preferences in high $\mathrm{K}$ individuals and the paternity uncertainty rationale for the hypothesis about the moderating influence of LH strategies and sociosexuality are highly specific and certainly not the most parsimonious. A less complex explanation is that since high $\mathrm{K}$ individuals are simply choosier when assessing potential mates (e.g., Dillon et al., 2013), they tend to create greater differentiation between various mating options, 
including physical characteristics such as the eye colour. Again, this choosiness might be potentiated by some fitness-irrelevant factors that result in specific features of blue-eyed males, as discussed above. In the current study we will not evaluate these explanations against each other. Rather, we will test the more general hypothesis about the importance of LH strategies and sociosexuality for the variation in the blue-like-blue effect.

To summarize, the main aim of the current research is to conduct a close replication of Laeng et al. (2007) study, this time in a Croatian sample that has a lower ratio of blue- compared to brown-eyed individuals. The blue-like-blue hypothesis states that blue-eyed men find more attractive and more often have blueeyed women as partners, while brown-eyed men and women, regardless of eye colour, show no such preferences and pairing outcomes. Note that the preferences effect was recently replicated by Bressan (2020), as a side finding of a study focused on sexual imprinting, but without a corresponding finding observed for actual partner choices. Another aim of our study is to test whether LHS and sociosexuality moderate the blue-like-blue effect when it comes to expressed preferences. We hypothesized that the preference for blue eyes is higher in those blue-eyed men who are characterized by a slower LHS or are sociosexually more restricted, than those who apply a faster LHS or are sociosexually unrestricted. No such interactions were hypothesized for brown-eyed men and for women.

\section{Participants}

\section{Method}

The majority of the sample consisted of psychology students at the Faculty of Humanities and Social Sciences at the University of Rijeka. In addition, due to a lack of (mainly) blue-eyed men, the students were asked to recruit their acquaintances, partners, friends, family members, etc. The students received course credits for both participation and recruitment. In total, 321 individuals participated in this study. One hundred sixty-six were brown-eyed (51.7\%), 89 blue-eyed (27.7\%), and 66 greeneyed $(20.6 \%)$. Eighty-three participants were excluded from further analysis for several reasons: 47 because they failed an attention check; 25 because they used their smartphones or other devices except for a PC, laptop or tablet, as required in the recruitment letter and study instructions; 11 participants whose sexual orientation was not hetero- or bisexual were also excluded, due to small sample size of that group. The remaining participants $(N=238)$ were divided into two overlapping samples - a smaller sample to test for blue-eyed preference $(n=128)$ and a sample of those involved in a romantic relationship to test for AM $(n=138)$.

The recruitment of the blue-eyed males ran much slower than the recruitment of participants within the other three categories. Therefore, the recruitment of the full sample continued until we reached a number of 32 blue-eyed males, which was 
slightly above the pre-defined minimal number of participants in each group based on the expected minimal effect size of $d=1.11$ observed by Laeng et al. (2007). "Hazel" eye colour was merged with the brown-eyed category and "blue-grey" eye colour with the blue-eyed category. Participants with "brown-green" and "bluegreen" eyes were merged with the brown- and blue-eyed categories, respectively. For the analysis of the data from the experimental part of the study we aimed to have equal numbers of participants within each group ( 32 blue- and brown-eyed men and 32 blue- and brown-eyed women). To that aim, we included in the analysis 32 participants from each group who were the first to finish the study (after that number was reached for the blue-eyed males group). Thus, the sample in the experimental part included 128 participants, with 32 blue-eyed and 32 brown-eyed individuals of each sex. Of these, 121 participants were heterosexual (94.5\%) and 7 were bisexual (5.5\%). The age of the participants ranged from 18 to 43 years $(M=22.84 ; S D=$ 4.19). The sample on which the AM hypothesis was tested included 138 (61 male and 77 female) participants (age range 18 to 50 years; $M=22.95 ; S D=4.72$ ). Out of the previously remaining 238 , another 93 were excluded for not satisfying the criterion of currently being involved in a romantic relationship for at least 6 months, and finally, 7 bisexual participants were excluded because we did not know the gender of their partners.

\section{Stimuli}

Sixty photographs were selected from two databases of facial expressions: The Max Planck FACES Database (Ebner et al., 2010) and Young Adult White Faces with Manipulated Versions (DeBruine \& Jones, 2017); 15 of each blue- and browneyed young men and women (age up to 30 years). While it would have been ideal to use only one database, neither included enough photographs of interest, so they were combined. The pictures were full frontal close-ups of the emotionally neutral faces. Each photograph was manipulated using Adobe Photoshop CS3 so as to create a "clone" with the other eye colour. No other manipulations were made. Therefore, the final set consisted of 120 photographs ( 60 original and 60 of faces with manipulated eye colour). An example of the stimuli used can be seen in Figure 1.

A short pilot study was conducted to test whether the eye-colour manipulations were successful. Nine female and one male psychology student (who later did not participate in the main study) were shown a set of 60 pictures: 30 natural and 30 manipulated ones. No participant saw a model with both eye colours. They were asked two questions: "Do you notice anything unusual about these pictures and, if yes, what?" and "Do you notice anything unusual regarding the persons' eyes and, if yes, what?" Response time was unlimited and the participants could skip back and forth among the pictures, as well as zoom in if they wished. No participant made any comments about eye colour. At the end of the main study, all participants were given the option to leave a comment on the pictures used, but none did. Altogether, this 
suggests that the manipulations were successful, i.e., that the pictures appeared as natural to the participants.

\section{Figure 1}

\section{Examples of Stimulus Pictures}
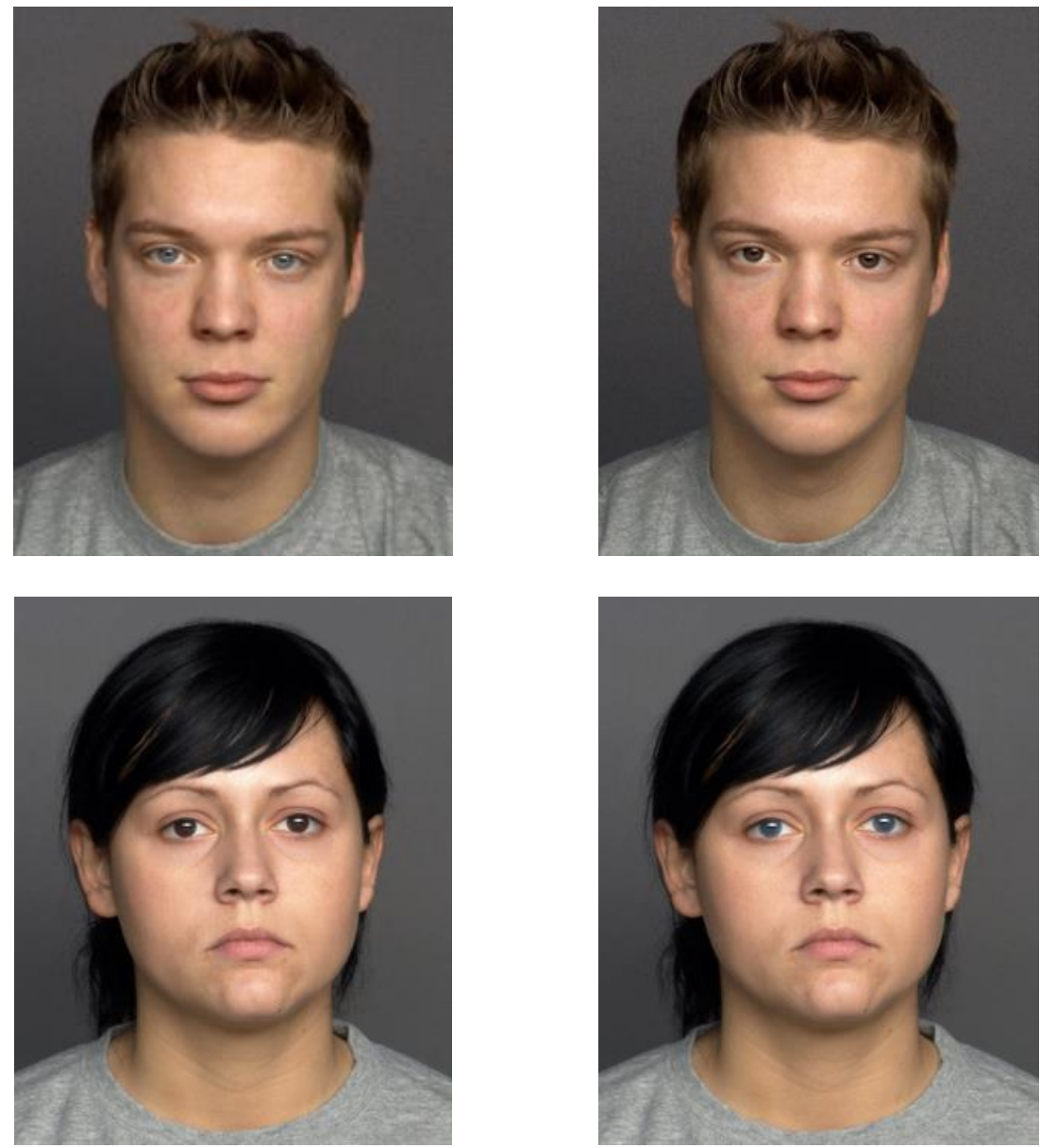

Note. Natural eye colour is shown on the left and manipulated eye colour on the right.

\section{Measures}

The Mini-K Scale of Life History Strategies (Figueredo et al., 2006) assesses a single fast-slow life history strategy dimension. It is a short version of the Arizona Life History Battery (ALHB; Figueredo et al., 2007), and because it includes items from all the scales of the ALHB, it can be used as a convenient substitute for the entire ALHB. It includes 20 items (e.g., "I avoid taking risks"; "I have a close and 
warm romantic relationship with my sexual partner") that measure 7 theoretical aspects of LHS: (a) family social contact and support; (b) friends social contact and support; (c) altruism; (d) mother/father relationship quality; (e) insight, planning, and control; (f) intentions toward infidelity, and (g) religiosity and involvement in the local community. Responses are given on a Likert-type scale with answers ranging from -3 (completely disagree) to 3 (completely agree). Higher scores indicate slower LHS. In comparison to the full ALHB, the Mini-K has limited inter-item consistency and test-retest reliability ( .70) due to the reduced number of items as well as the conceptual breadth of the underlying construct. However, when used with the full ALHB, the Mini-K typically has the highest loading (compared to other scales) on the common K-Factor extracted from all the ALHB scales (Figueredo et al., 2007). In the current study, the Croatian version of the scale was used (Gračanin et al., 2018). Internal consistency in both the initial validation and the current study was satisfactory (Cronbach alpha $=.77)$.

Sociosexual Orientation Inventory - SOI (Simpson \& Gangestad, 1991) is a 7item measure of sociosexuality, which pertains to individual differences in willingness to engage in casual, uncommitted sexual relationships. Sociosexuality may be treated as a single dimension (see also Penke \& Asendorpf, 2008). Two items ask respondents to report on their past sexual behaviour: the number of sexual partners in the past year and the number of times they have had sex with someone on only one occasion. One item assesses future sexual behaviour (the number of partners anticipated in the next 5 years). Another, answered on a 7-point Likert-type scale, inquires about sexual fantasies (how often they fantasize about having sex with someone other than their current or most recent romantic partner). Three more items, all answered on Likert-type scales, ask about respondents' attitudes toward engaging in casual sex. The total score is calculated as a differentially weighted sum and can range from 10 (maximally restricted orientation) to 1000 (maximally unrestricted orientation). In student samples, it normally ranges from 10 to 250, with men scoring higher than women. In the initial validation, the SOI was proven to be internally consistent (Cronbach alpha $=.75)$ and test-retest reliability over 2 months was high $(r=.94 ;$ Simpson \& Gangestad, 1991). A Croatian version of the SOI used in the current study was validated by Kardum et al. (2006). A confirmatory factor analysis supported a one-factor solution. Cronbach alpha in a sample of 297 male and 316 female participants was .77. In this study it was .80 .

\section{Procedure}

The study was conducted using Qualtrics online survey software. Each participant used their own PC, laptop, or tablet and accessed the study via a hyperlink shared by the experimenter. Participants were instructed not to access the study via smartphones or similar devices. This was important because the stimuli would appear smaller than intended if on a small screen and the eye colour of the model would be harder to detect. First, participants were informed about the aims of the study and 
were guaranteed anonymity, followed by a brief questionnaire inquiring about their age, sex, and sexual orientation. The next part was the replication of the experimental procedure used by Laeng et al. (2007): the 120 pictures were divided into four sets. Two sets contained only pictures of men and the other two only pictures of women. Each set contained an equal number of models with "natural" and "altered" versions of eye colour. Only one of the alternate copies of each model was included in a set so that every participant would see each model in only one eye-colour version. If their sexual orientation was hetero- or bisexual, participants were shown at random one of the two sets containing 30 models of the opposite sex. Homosexual participants were shown at random one of the two sets containing models of the same sex (data not analysed). Within these sets, the pictures were presented in random order for each participant. Participants rated the attractiveness of each model using a Likert-type scale, with 1 meaning Not attractive at all and 5 meaning Very attractive. Next, the SOI and Mini-K were administered. Finally, participants were asked about their natural eye colour, relationship status and duration, and the natural eye colour of their partner (the partners' eye colour categories were created in the same way as those described in the Participants section).

\section{Results}

Both male and female participants' average attractiveness ratings were relatively low (not greater than 2.25 on a scale from 1 to 5; Table 1$)$. No outliers $(+2$ $S D)$ were detected in any participant group. Only one blue-eyed female participant was excluded from further analysis, because she rated all 30 of the models, regardless of their eye colour, as "Not at all attractive". Another randomly selected blue-eyed female participant was entered in the analysis instead.

\section{Table 1}

Descriptive Statistics and Correlations Between Attractiveness Ratings, LHS, Sociosexuality, and Participant's Eye Colour, Calculated Separately for Male and Female Participants

\begin{tabular}{|c|c|c|c|c|c|c|}
\hline & \multicolumn{6}{|c|}{ Male participants } \\
\hline & $M$ & $S D$ & 1. & 2. & 3. & 4. \\
\hline $\begin{array}{l}\text { 1. Attractiveness rating of } \\
\text { blue-eyed women }\end{array}$ & 2.25 & 0.80 & 1 & & & \\
\hline $\begin{array}{l}\text { 2. Attractiveness rating of } \\
\text { brown-eyed women }\end{array}$ & 2.11 & 0.63 & $.71^{* *}$ & 1 & & \\
\hline 3. LHS (Mini-K) & 0.90 & 0.75 & .13 & .11 & 1 & \\
\hline 4. Sociosexuality (SOI) & 59.23 & 27.75 & .09 & -.02 & $-.38^{* *}$ & 1 \\
\hline 5. Participant eye colour & / & / & -.09 & .12 & $.28^{*}$ & -.14 \\
\hline
\end{tabular}




\begin{tabular}{lcccccc}
\hline & \multicolumn{7}{c}{ Female participants } \\
\cline { 2 - 6 } & $M$ & $S D$ & 1. & 2. & 3. & 4. \\
\hline $\begin{array}{l}\text { 1. Attractiveness rating of } \\
\text { blue-eyed men }\end{array}$ & 2.01 & 0.61 & 1 & & & \\
$\begin{array}{l}\text { 2. Attractiveness rating of } \\
\text { brown-eyed men }\end{array}$ & 1.94 & 0.59 & $.78^{* *}$ & 1 & \\
3. LHS (Mini-K) & 1.25 & 0.54 & -.15 & -.05 & 1 & \\
4. Sociosexuality (SOI) & 39.61 & 20.13 & -.02 & -.03 & .10 & 1 \\
5. Participant eye colour & $/$ & $/$ & -.09 & -.13 & .03 & -.14 \\
\hline
\end{tabular}

${ }^{*} p<.05,{ }^{* *} p<.01 ;$ participants' blue eyes were coded as 0 and brown eyes as 1.

In order to test the hypothesis that blue-eyed men find blue-eyed women more attractive, while brown-eyed men and women, regardless of eye-colour, show no such preferences, a repeated measures ANOVA was performed with ratings of attractiveness as the dependent variable. The within-subject independent variable was the eye colour of the model, while between-subject independent variables were participant's sex and eye colour. The analysis revealed a significant main effect of model eye colour. The participants rated as more attractive blue-eyed $(M=2.13 ; S D$ $=0.70)$ than brown-eyed $(M=2.03 ; S D=0.61)$ models, regardless of their own sex or eye colour $\left(F_{1,252}=5.70 ; p<.05 ; \eta_{p}{ }^{2}=.021\right)$. The main effects of participant's sex $\left(F_{1,252}=0.66 ; p=.42 ; \eta_{p}{ }^{2}=.003\right)$ and eye colour $\left(F_{1,252}=1.94 ; p=.16 ; \eta_{p}{ }^{2}=.008\right)$ were insignificant. Crucially, the analysis also revealed a significant three-way interactive effect between the sex and eye colour of participant's and model's eye colour $\left(F_{3,248}=3.83 ; p<.05 ; \eta_{p}^{2}=.046\right.$; see Figure 2$)$.

\section{Figure 2}

Mean Attractiveness Ratings of Opposite-Sex Models with Blue or Brown Eyes, for Male (Left Panel) and Female (Right Panel) Participants with Blue and Brown Eyes
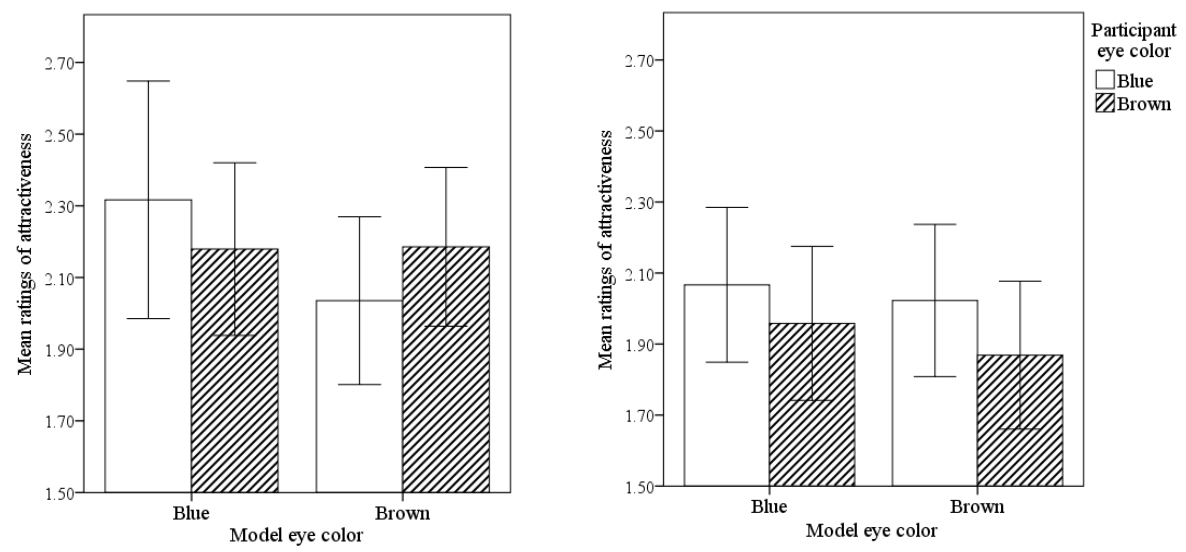

Note. Vertical lines indicate $95 \%$ confidence intervals. 
Bonferroni post-hoc tests revealed that blue-eyed male participants rated blueeyed female models $(M=2.32 ; S D=1.19)$ as more attractive than brown-eyed ones $\left(M=2.04 ; S D=0.65 ; p<.05 ; \eta_{p}{ }^{2}=.044\right)$, while it revealed no significant differences in attractiveness ratings among other groups of participants ( $p$ s: .49 - .54). Thus, the significance of the main effect for blue-eyed preference can probably be accounted for by the significance of this three-way interactive effect. The results did not change significantly when stimulus set (natural/edited) was controlled for. Therefore, the effect found by Laeng et al. (2007) was successfully replicated, although it was notably smaller.

In order to test for AM by eye colour, a chi-square test was performed. In contrast to our hypothesis, no statistically significant effect of AM was found for blue, brown, and green-eyed male participants and their female partners $\left(\chi^{2}=4.46\right.$; $d f=4 ; p=.35)$. The same goes for female participants and their male partners $\left(\chi^{2}=\right.$ $7.12 ; d f=4 ; p=.13)$. Therefore, the findings about the existence of AM in blue-eyed males from Laeng et al. (2007) were not replicated.

To test for the moderating effects of LHS and sociosexuality, $z$-scores for each scale were calculated separately for male and female participants and these were used to create four interaction terms (male participant's eye colour x LHS / sociosexuality and female participant's eye colour x LHS / sociosexuality). Multiple hierarchical regression analyses were performed with the attractiveness rating of the blue-eyed models as a criterion, while attractiveness rating of brown-eyed models was entered as a predictor (i.e., controlled for) in the first step of the analyses. In this way we accounted for the between-subject variation in attractiveness ratings irrespective of eye colour which was not relevant for our hypotheses. The second step in each model included participant's eye colour and either LHS or sociosexuality, and the third step the interaction term of participant's eye colour and either LHS or sociosexuality. Table 2 shows the results of hierarchical regression analyses for male participants.

Table 2

Results of Hierarchical Regression Analyses for Male Participants' Attractiveness Rating of Blue-Eyed Women

\begin{tabular}{llll}
\hline \multicolumn{1}{c}{ Predictors } & $\boldsymbol{\beta}$ & $\boldsymbol{R}^{\mathbf{2}}$ & $\boldsymbol{\Delta \boldsymbol { R } ^ { \mathbf { 2 } }}$ \\
\hline Step 1 & & $.50^{* *}$ & \\
$\quad$ Attractiveness rating of brown-eyed women & $\mathbf{. 7 1}^{* *}$ & & \\
\hline Step 2 & & $.54^{* *}$ & $.04^{*}$ \\
Attractiveness rating of brown-eyed women &. $\mathbf{. 2}^{* *}$ & & \\
Participant eye colour & $\mathbf{- . 2 0 ^ { * * }}$ & & \\
LHS & .11 & & \\
\hline Step 3 & & $.59^{* *}$ & $.05^{*}$ \\
Attractiveness rating of brown-eyed women & $\mathbf{. 7 2}^{* *}$ & & \\
Participant eye colour & $\mathbf{. 1 9}^{*}$ & & \\
LHS & $\mathbf{. 2 2}^{*}$ & & \\
Participant eye colour x LHS & $\mathbf{. . 2 1}^{*}$ & & \\
\hline
\end{tabular}


PSYCHOLOGICAL TOPICS, 30 (2021), 1, 31-56

\begin{tabular}{llll}
\hline \multicolumn{1}{c}{ Predictors } & $\boldsymbol{\beta}$ & $\boldsymbol{R}^{\mathbf{2}}$ & $\boldsymbol{\Delta R}^{\mathbf{2}}$ \\
\hline Step 1 & & $.50^{* *}$ & \\
$\quad$ Attractiveness rating of brown-eyed women & $\mathbf{. 1}^{* *}$ & & \\
\hline Step 2 & & $.54^{* *}$ & .04 \\
Attractiveness rating of brown-eyed women &. $\mathbf{7 3}^{* *}$ & & \\
Participant eye colour & -.16 & & \\
Sociosexuality & .08 & & \\
\hline Step 3 & & .54 & .00 \\
Attractiveness rating of brown-eyed women &. $\mathbf{7 3}^{* *}$ & & \\
Participant eye colour & -.16 & & \\
Sociosexuality & .07 & & \\
Participant eye colour x sociosexuality & .06 & & \\
\hline
\end{tabular}

${ }^{*} p<.05,{ }^{* *} p<.01$; participants' blue eyes were coded as 0 and brown eyes as 1 .

In males, the attractiveness rating of brown-eyed women was a significant positive predictor of the attractiveness rating of blue-eyed women $(\beta=.71-.73 ; p<$ .001). When testing for the moderating effect of LHS, participant eye colour was $(\beta=$ $-.20 ; p<.05)$, while LHS was not $(\beta=.11 ; p=.25)$ a significant predictor. Blue-eyed participants rated the blue-eyed models as more attractive than the brown-eyed participants did. These variables explained a significant additional amount of variance in the attractiveness rating of blue-eyed models $\left(\Delta R^{2}=.04 ; p<.05\right)$. As hypothesized, the interaction between participant's eye colour and LHS significantly predicted the attractiveness rating of blue-eyed women ( $\beta=-.21 ; p<.05)$, accounting for another $5 \%$ of variance in these ratings. Specifically, as evident from a simple slope analysis (see Figure 3), the higher the blue-eyed men's score on the Mini-K, or rather, the

\section{Figure 3}

The Effects of an Interaction Between Participant's Eye Colour and Life History Strategy on the Attractiveness Rating of the Blue-Eyed Women

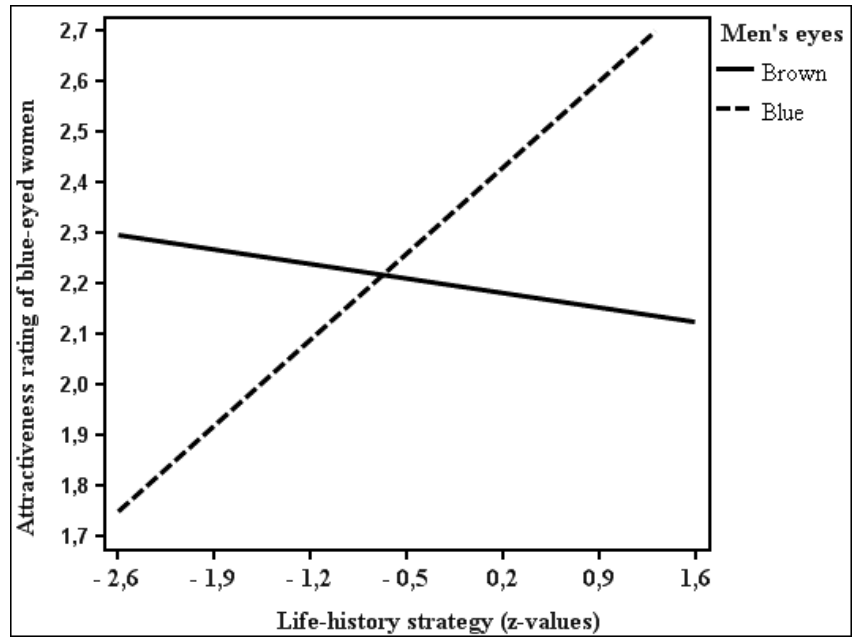


slower their LHS, the more attractive they rated the blue-eyed female models ( $b=.24$, $p<.05)$. On the other hand, the brown-eyed men did not rate the attractiveness of blue-eyed women differently depending on their LHS $(b=-.04, p=.40)$. In addition, LHS became a significant positive predictor in this step $(\beta=.22, p<.05)$, which corresponds to the observed zero-order correlation between the two (Table 1).

Unexpectedly, when entered as predictors in the second block, eye colour of participants and sociosexuality did not significantly explain an additional amount of variance in attractiveness rating of blue-eyed models $\left(\Delta R^{2}=.04 ; p=.10\right)$. Also, contrary to expectation, no significant interactive effect of participant's eye colour and sociosexuality was observed $(\beta=.06 ; p=.48)$. In Table 3 , the results of hierarchical regression analyses for female participants are shown.

\section{Table 3}

Results of Hierarchical Regression Analyses for Female Participants' Attractiveness Rating of Blue-Eyed Men

\begin{tabular}{|c|c|c|c|}
\hline Predictors & $\boldsymbol{\beta}$ & $\boldsymbol{R}^{2}$ & $\Delta R^{2}$ \\
\hline Step 1 & & $.60^{* *}$ & \\
\hline Attractiveness rating of brown-eyed men & $.78^{* * * *}$ & & \\
\hline Step 2 & & $.62^{* *}$ & .01 \\
\hline Attractiveness rating of brown-eyed men & $.77^{* *}$ & & \\
\hline Participant eye colour & .01 & & \\
\hline LHS & -.11 & & \\
\hline Step 3 & & $.62^{* *}$ & .00 \\
\hline Attractiveness rating of brown-eyed men & $.77^{* * *}$ & & \\
\hline Participant eye colour & .01 & & \\
\hline LHS & -.11 & & \\
\hline Participant eye colour x LHS & -.01 & & \\
\hline Predictors & $\beta$ & $\boldsymbol{R}^{2}$ & $\Delta R^{2}$ \\
\hline Step 1 & & $.60^{* *}$ & \\
\hline Attractiveness rating of brown-eyed men & $.78^{* * *}$ & & \\
\hline Step 2 & & $.60^{* * *}$ & .00 \\
\hline Attractiveness rating of brown-eyed men & $.78^{* *}$ & & \\
\hline Participant eye colour & .01 & & \\
\hline Sociosexuality & .01 & & \\
\hline Step 3 & & $.61^{* *}$ & .01 \\
\hline Attractiveness rating of brown-eyed men & $.78^{* * *}$ & & \\
\hline Participant eye colour & .01 & & \\
\hline Sociosexuality & .00 & & \\
\hline Participant eye colour $\mathrm{x}$ sociosexuality & -.09 & & \\
\hline
\end{tabular}

${ }^{*} p<.05,{ }^{* *} p<.01$; participants' blue eyes were coded as 0 and brown eyes as 1 .

Attractiveness rating of brown-eyed men was a significant positive predictor of attractiveness rating of blue-eyed men $(\beta=.77-.78 ; p<.001)$. As predicted, female participant's eye colour and LHS / sociosexuality as well as the interaction between 
eye colour and LHS or sociosexuality did not significantly predict attractiveness ratings of blue-eyed models after controlling for the attractiveness rating of browneyed models. We also performed all the analyses by controlling for the stimulus set in the first step of the regressions. The results remained the same as those reported above.

\section{Discussion}

The goal of the current research was (a) to replicate the study conducted by Laeng et al. (2007) that found preferences for blue-eyed women in blue-eyed men and a corresponding pattern in AM (blue-like-blue effect) and (b) to explore the moderating effects of LHS and sociosexuality on these preferences. We expected that blue-eyed men would show preferences for blue-eyed women, while for browneyed men and for women, regardless of their eye colour, this effect would not be observed. The same was hypothesized for romantic relationship formation. In other words, this pattern was also expected to hold for the AM. Finally, we expected that the effect of participants' eye colour on their eye-colour preference would be stronger in slow LHS and sociosexually restricted males.

Consistent with the blue-like-blue hypothesis and the results of the study by Laeng et al. (2007), blue-eyed male participants rated the blue-eyed women as more attractive than brown-eyed women. No differences in attractiveness estimates were found for brown-eyed men and for women, regardless of eye colour. Thus, we were able to replicate the preference part of the blue-like-blue effect, by using relatively similar methodology as Laeng et al. (2007), but in different population and geographical region. However, the effect was small in size and also smaller than in the study by Laeng et al. (2007), in which it was large. The size of the blue-like-blue effect for preferences is not in line with our expectations, because we predicted that the effect size should be equal or larger in a Croatian sample compared to the Norwegian sample of Laeng et al. (2007), given that blue-eyed individuals make up for a significantly smaller portion of Croatian population. In this case, a preference for blue-eyed women in blue-eyed men would prove even better protection against cuckoldry, since the odds of the lover and real father of the child also being blueeyed are significantly lower (Laeng et al., 2007). Such finding might speak against the paternity uncertainty account of this (partly) replicated finding. Alternatively, the observed small effect size can be ascribed to generally low ratings of attractiveness across all groups of participants and models in this study. While Laeng et al. (2007) photographed volunteers themselves and could probably be more selective in choosing their models regarding general attractiveness, we opted for using pictures of individuals with neutral expressions from standardized picture sets. The criteria for selection of the pictures were very specific (young models, well visible eye colour, and exactly 15 blue- / brown-eyed males and females), so we couldn't afford to be choosy regarding general attractiveness of the models, which is the most likely 
reason for the lower attractiveness estimates in this study (means ranging from 1.94 to 2.32) compared to that of Laeng et al. (2007; means ranging from 2.60 to 3.29). This is supported by the fact that several male participants commented spontaneously on the low attractiveness of the models. If a certain model was highly unattractive, the eye colour manipulation would have less influence on rated attractiveness, making them less discriminative for eye colour preference than averagely attractive models. In fact, several of the models from the current study, particularly female ones, were rated by almost all male participants as highly unattractive, regardless of the eye colour they were presented with. With this in mind, even the small effect that was observed is likely to be an indicator that the effect truly exists in the population, and therefore, its size does not necessarily speak against the paternity uncertainty account.

The hypothesis that blue-eyed men would mate assortatively with blue-eyed women more frequently than one would expect by chance, was not supported. In fact, no assortative mating by eye colour was found in our sample, neither in men nor women. Then, what is the significance of the blue-eyed preference that was found in blue-eyed men, if this preference does not translate into an actual assortment? A number of factors may have influenced these results, the first being sample size. It is possible that the small size of the preference effect is real, rather than the methodological artefact, and thus, it wasn't large enough to significantly influence AM in an overlapping and only a somewhat larger sample of just 138 participants. The AM sample of Laeng et al. (2007) was more than three times larger $(N=443)$, and the effect for blue-eyed preference was significantly larger as well. Another factor is the ratio of eye colour phenotypes in each population. While we hypothesized that a larger effect for blue-eyed preference could be expected in Croatia than in Norway because blue-eyed individuals make up a smaller part of the population, this also means that there are fewer "available" blue-eyed individuals in the Croatian population, which might decrease chances for pairing based on this particular trait. Importantly, other studies of eye-colour preferences obtained a similar pattern of results in that the preferences did not necessarily translate into a choice of a partner in real life (Bovet et al., 2012; Bressan, 2020), or simply that there is no AM in the eye colour (Prokop et al., 2010). Relatedly, many other factors, potentially much more important than eye colour, influence mate choice and mate retention: most people want partners who are physically attractive, who share their beliefs and values (Watson et al., 2004), and display socially desirable personality traits (e.g., agreeableness; Meier et al., 2010). Men tend to place greater emphasis on physical attractiveness, whereas women tend to stress personal characteristics such as kindness, considerateness, and earning capacity (Schmitt, 2014). When these factors are taken into consideration, it is understandable that blue eye colour, and possibly the paternity certainty that it might offer blue-eyed men if they were to choose a blue-eyed partner, is not necessarily a priority. Also, some other characteristics of potential partners, such as signs of a potential for faithfulness may increase paternity certainty as well. Even in the context of prostitution, as an extreme 
example of short-term mating, men prefer women with less sexual experience (Sohn, 2016). If these other factors have larger effects on mate choice, it is possible that a small preference for blue-eyed women does exist in blue-eyed men, but is not strong enough to have any effects on AM, or, even if it does have such effects, that they would not be observed in a small sample such as ours. Finally, for AM to occur, both genders would have to show preferences toward particular feature, or, the gender expressing particular preferences would have to have substantial priority in partner selection. The former is not evident from our results and the latter is certainly not the case.

The hypothesis about stronger blue-like-blue effect in men who apply a slower LHS was confirmed. Blue-eyed male participants with a slow reproductive strategy rated blue-eyed women as more attractive than brown-eyed women to a significantly larger extent than it was the case with fast LHS males. LHS had no effects on attractiveness ratings in the brown-eyed male and in female participants, neither as main effects nor in interaction with participants' eye colour. However, the hypothesis about the greater blue-like-blue effect in more sociosexually restricted men was not supported. While sociosexual orientation and LHS are theoretically related constructs, they typically have only a low to medium inter-correlation (Dunkel \& Decker, 2010; Strouts et al., 2016), as was also shown in the current study. Therefore, the same links of these constructs with other variables cannot be always expected. LHS are a broad psychological construct: the Mini-K taps into individual differences ranging from altruism and infidelity intentions to religiosity and involvement in the local community (Figueredo et al., 2007). On the other hand, sociosexual orientation is a relatively narrow construct encompassing only specific aspects of human sexual behaviour - promiscuity (past and plans for the future) and attitudes towards it (Simpson \& Gangestad, 1991). Apparently, the aspects of LHS other than those pertaining to sociosexual strategies seem to have a critical role in the particular attractiveness ratings of the opposite-sex individuals. Probably, these aspects are related to higher investment in offspring (Figueredo et al., 2006; Stearns, 1976), which might be also expected to be accompanied by cuckoldry avoiding or some other mating mechanisms. Certainly, promiscuous behaviour and attitudes, as measured by the SOI, are potentially related to less investment in offspring, and as such, we expected them to predict eye-colour preferences in blue-eyed males in the same way as LHS. However, if males are generally more inclined towards unrestrictive strategy, a successful employment of certain aspects of the K strategy might actually provide them with more possibilities for unrestricted sociosexual behaviour, which is exactly what was shown in studies that explored links between LH-related personality traits and sociosexuality. For example, higher extraversion reflects slow LHS (Figueredo et al., 2007), while at the same time it positively predicts unrestricted sociosexuality (Schmitt \& Shackelford, 2008). Similarly, higher mate value, which is a hallmark of slow LHS, is linked with more unrestricted sexual behaviour (Penke \& Denissen, 2008). Therefore, while fast LHS and unrestricted sociosexual behaviour are expected to be positively related from the theoretical point 
of view, some aspects of sexual behaviour in slow LHS males might often create a more orthogonal relationship between the measures of these constructs, also resulting in their different relationships with third variables.

As stated above, there are several possible explanations of the preference part of the blue-like-blue effect observed in the current study and that of Laeng et al. (2007) and Bressan (2020). The paternity uncertainty account is based on the idea that recessive physical characteristics with salient and reliable mechanisms of inheritance, like the blue eye colour, can facilitate the male preference for women with the same characteristics. Mating with these women offers the man a higher paternity certainty and protection against cuckoldry (Laeng et al., 2007). The same could be true for other recessive physical characteristics with salient inheritance, like a straight hairline (as opposed to the dominant widow's peak), free ear lobes (vs dominant attached ones) or the lack of cheek dimples (vs dominant appearance of the same; McKusick, 1966). It is possible that a preference for these characteristics would not appear in their male carriers like it does for the blue eye colour, because people tend to pay more attention to eyes and consequently to their colour, in comparison to other facial features. However, with the mechanisms of their inheritance being very similar or identical to eye colour, a smaller effect might still be observed. A study performed by Bovet et al. (2012) was the one that got closest to this idea: the authors explored whether males prefer a group of recessive facial features or alternatively, whether they prefer features similar to themselves, with the latter receiving substantially more support. The former hypothesis actually represents a more general variant of the paternity uncertainty hypothesis, and it might seem that the findings of that study are inconsistent with the blue-like-blue effect. However, that study did not focus on the differences in preferences of blue- and brown-eyed men, and thus, the homogamy-like pattern observed in their study actually does not exclude the existence of the blue-like-blue effect, but it rather supports it.

The paternity uncertainty account relies heavily on the assumption that sexual infidelity which results in offspring is not a rare occurrence, or at least it wasn't in our evolutionary past (Laeng et al., 2007). Numerous authors agree that infidelity is a relatively common phenomenon, with estimates of its presence ranging from being very low (only a few per cent) to as much as $75 \%$ of all couples, depending on age, relationship duration, culture, time period, and other parameters (Laumann et al., 1994; Shackelford et al., 2000). Perhaps most importantly, the cuckoldry rate, at least for Western human populations, is probably around 1\% (Anderson, 2006). Thus, it appears that non-paternity as a result of infidelity is not negligible, although it is certainly lower than it was reported in earlier studies (e.g., Baker \& Bellis, 1995). At the same time, paternal certainty positively correlates with actual paternity (Anderson, 2006), and males are able to use paternity cues (e.g., physical resemblance) when investing in children (Heijkoop et al., 2009). These facts may speak in favour of the existence of certain evolved anti-cuckoldry mechanisms, also supporting the idea that the blue-like-blue effect might be understood in that way. 
However, there are several reasons to doubt paternity uncertainty account in the current context. For example, Prokop et al. (2010) found that paternal investment was not higher in blue-eyed couples (and there was no AM for blue eyes) compared to couples with other eye colour combinations (but note that blue-eyed males from our sample had significantly slower LHS, which also implies a proneness to higher parental investment). From the developmental perspective, the fact that the eye colour of infants typically changes within the first 6-12 months of life (Matheny \& Dolan, 1975) represents another argument against the paternity uncertainty hypothesis. Finally, the smaller size of the blue-like-blue effect in Croatian than in the Norwegian sample discussed above may also speak against such explanation.

The paternity uncertainty account was the main rationale for the blue-like-blue hypothesis proposed by Laeng et al. (2007). While our study replicated the preference aspect of the blue-like-blue effect, this does not mean that the rationale offered by Laeng et al. (2007) represents the only, and as seen from the previous section, the most plausible explanation of that finding. As stated above, pleiotropic effects of genes coding for blue eyes and other aspects of body pigmentation could be evident in certain individual psychological characteristics that influence eye colour preferences outside of the context of paternity certainty assurance. Similarly, the reason behind the possibility that the blue-like-blue effect is larger in high $\mathrm{K}$ individuals, which is an additional contribution of the current study, might be (a) fitness-relevant because it brings benefits such as the promotion of paternal certainty, which is clearly more important in high $\mathrm{K}$ individuals, (b) fitness-relevant because of homogamy preferences in high $\mathrm{K}$ individuals (possibly via sexual imprinting), that is more potentiated in blue-eyed individuals due to the pleiotropic effects of genes coding for blue eyes (e.g., the interaction between personality and some cultural inputs) or (c) completely irrelevant in relation to fitness and simply reflecting greater choosiness of high $\mathrm{K}$ individuals interacting with the same pleiotropic effects. Note that in (b) or (c) the effect is expected to occur in males simply because they, in contrast to females, place greater importance on physical characteristics of potential mating partners.

Perhaps the most important implication of the current results is that individual differences in traits that are deeply rooted in evolutionary history, like LHS, can influence the way certain more recent adaptations are related to mating behaviour. Life History Theory is a unifying principle in evolutionary biology, and the problems of strategic allocation of resources among the demands of survival and reproduction to which differential LHS are the answer (Figueredo et al., 2006) are as old as sexual reproduction itself, while differential LHS observed in humans are probably as old as the human race. Blue-eyes (and potentially the preferences for them in blue-eyed men) could not have developed more than 6000 - 10000 years ago. In case the bluelike-blue effect is based on an evolved adaptive mechanism, it appears that its activation is largely dependent on whether men apply faster or slower LHS. 


\section{Limitations and Future Directions}

The first limitation of the current study is that we assessed preferences for eye colour by asking participants only one straightforward question about the attractiveness of the models. In addition to more differentiated self-report measures, future studies should assess other indicators of attractiveness, such as attention focus and eye-gaze latency. Humans tend to pay more attention to more attractive faces from the earliest age (Slater et al., 1998), which can be exploited to create a behavioural measure of attractiveness in a particular context. Another limitation is that, when exploring AM, we focused exclusively on the currently dating/married couples that were in a relationship for at least 6 months. More theoretically relevant results could have been gained if we focused on both current and all previous relationships that an individual had (see e.g., Štěrbová et al., 2019). Certainly, further testing of the AM hypothesis should also be done on larger samples.

The paternity certainty rationale for the blue-like-blue effect is based on the idea that it represents an evolved psychological adaptation. For an attribute to represent an adaptation, it has to promote fitness and to have elements of a special design, in that it is, for example, efficient, complex, highly specialized, and universal across certain species (Williams, 1966). In order to explore whether the particular attribute has these and other adaptation-relevant features, there is a need to evaluate support from various sources of evidence, ranging from well-grounded theoretical assumptions to empirical data from psychological, physiological, and other domains that constitute the interdisciplinary approach typical of evolutionary psychology (Schmitt \& Pilcher, 2004). Theoretical evidence for the existence of blue-like-blue adaptation comes from the potential utility of this mechanism in prevention of cuckoldry, which clearly promotes fitness. This argument was further supported not just by the empirical psychological evidence from Laeng et al. (2007) and our research, but also in computer-modelling study done by these authors. Our study also provided other psychologically relevant evidence by showing that blue-like-blue effect is dependent on reproductive strategies, which speaks in favour of the existence of the adaptive (anti-cuckoldry) mechanism. Future research could also additionally focus on questions such as whether blue-eyed males show higher paternal investment (see also Prokop et al., 2010). Next, the special design of such an adaptation would imply that the blue-like-blue effect should not appear in the context of friendship, that it should be more important for long- than for short-term mating (which is already indirectly supported by our findings on its interactive effects with LHS; see also Šterrbová et al., 2019), and that its mechanism is activated only (or more) in reproductively mature males. Genetic evidence could be gained by exploring the links between the specific genes coding for the blue eye colour with specific eye-colour preferences and other mating behaviours. Finally, the current study represents only a first step toward cross-cultural comparisons that are a necessary component of evaluating claims about the existence of adaptations. All this 
evidence should be contrasted with the evidence about the role of random individual differences or side effects of other adaptations, as discussed above.

\section{Conclusion}

In the experimental part of the study, the effect observed by Laeng et al. (2007) was successfully replicated, providing additional support for the preference aspect of the blue-like-blue effect. Blue-eyed men rated as more attractive blue-eyed than brown-eyed women, while brown-eyed men and women, regardless of eye colour, showed no preferences towards the models' eye colours. Sociosexuality was not a significant moderator of this effect, while LHS were - the slower the LHS of the blue-eyed men, the more attractive they rated the blue-eyed women compared to brown-eyed ones. No AM by eye colour was observed in participants and their romantic partners, thus making the replication of the blue-like-blue effect only partial. Aside from methodological explanations discussed above, we surmise that the main reasons for the differences in observations of this study and that of Laeng et al. (2007) are mainly due to the ratios of eye colour phenotypes in the Norwegian and Croatian populations as well as a small sample size in this study, particularly when testing for AM. The most important conclusion of the current research is that the eye colour preferences that are specific to blue-eyed males, and that represent either an anti-cuckoldry mechanism or some other adaptation, or even a random effect, are dependent on a mating-related personality trait that is deeply rooted in evolutionary history.

\section{References}

Anderson, K. G. (2006). How well does paternity confidence match actual paternity? Evidence from worldwide nonpaternity rates. Current Anthropology, 48, 511-518. https://doi.org/10.1086/504167

Baker, R. R., \& Bellis, M. A. (1995). Human sperm competition: Copulation, masturbation and infidelity. Chapman and Hall. https://doi.org/10.1007/978-3-319-16999-6_1957-1

Beals, R. L, \& Hoijer, H. (1965). An introduction to anthropology (3rd edition). MacMillan. https://doi.org/10.1002/ajpa.1330230437

Bereczkei, T., Gyuris, P., Koves, P., \& Bernath, L. (2002). Homogamy, genetic similarity, and imprinting: Parental influence on mate choice preferences. Personality and Individual Differences, 33, 677-690. https://doi.org/10.1016/S0191-8869(01)00182-9

Bovet, J., Barthes, J., Durand, V., Raymond, M., \& Alvergne, A. (2012). Men's preference for women's facial features: Testing homogamy and the paternity uncertainty hypothesis. PLoS ONE, 7(11), e49791. https://doi.org/10.1371/journal.pone.0049791 
Bressan, P. (2020). In humans, only attractive females fulfil their sexually imprinted preferences for eye colour. Scientific Reports, 10, 6004. https://doi.org/10.1038/s41598020-62781-7

Coplan, R. J., Coleman, B., \& Rubin, K. H. (1998). Shyness and little boy blue: Iris pigmentation, gender, and social wariness in preschoolers. Developmental Psychobiology, 32, 37-44. https://doi.org/10.1002/(SICI)1098-2302(199801)32:1<37:: AID-DEV4>3.0.CO;2-U

DeBruine, L. M. (2005). Trustworthy but not lust-worthy: Context-specific effects of facial resemblance. Proceedings of the Royal Society B, 272, 919-922. https://doi.org/10. 1098/rspb.2004.3003

DeBruine, L., \& Jones, B. (2017). Young adult white faces with manipulated versions. https://doi.org/10.6084/m9.figshare.4220517.v1

Dillon, H. M., Adair. L. E., Wanga, Z., \& Johnson, Z. (2013). Slow and steady wins the race: Life history, mate value, and mate settling. Personality and Individual Differences, 55, 612-618. https://doi.org/10.1016/j.paid.2013.05.015

Dunkel, C. S., \& Decker, M. (2010). Convergent validity of measures of life-history strategy. Personality and Individual Differences, 48, 681-684. https://doi.org/10.1016/j.paid. 2009.12.014

Ebner, N., Riediger, M., \& Lindenberger, U. (2010). FACES - A database of facial expressions in young, middle-aged, and older women and men: Development and validation. Behavior Research Methods, 42, 351-362. https://doi.org/10.3758/BRM. 42.1.351

Figueredo, A., Vasquez, G., Brumbach, B., Schneider, S., Sefcek, J., Tal, I., Hill, D., Wenner, C. J., \& Jacobs, W. J. (2006). Consilience and life history theory: From genes to brain to reproductive strategy. Developmental Review, 26, 243-275. https://doi.org/10.1016/j. dr.2006.02.002

Figueredo, A. J., Vásquez, G., Brumbach, B. H., \& Schneider, S. M. R. (2007). The K-factor, covitality, and personality: A psychometric test of life history theory. Human Nature, 18, 47-73. https://doi.org/10.1007/BF02820846

Figueredo, A. J., \& Wolf, P. S. A. (2009). Assortative pairing and life history strategy: A cross-cultural study. Human Nature, 20, 317-330. https://doi.org/10.1007/s12110-0099068-2

Forgaard, T. S., \& Dzamarjia, M. T. (2004). Innvandrerbefolkningen. In K. R. Tronstad (Ed.) Innvandring og invandrere 2004 (pp. 17-54). Statistisk Sentralbyrå.

Giosan, C. (2006). High-K strategy scale: A measure of the high-K independent criterion of fitness. Evolutionary Psychology, 4, 394-405. https://doi.org/10.1177/ 147470490600400131

Gračanin, A., Kardum, I., Hudek-Knežević, J., Krapić, N., \& Mehić, N. (2018, April 4-7). Can life history strategy predict assortment in personality traits? [Paper presentation]. 13th Conference of the European Human Behavior and Evolution Association, Pécs, Hungary. 
Gründl, M., Knoll, S., Eisenmann-Klein, M., \& Prantl, L. (2012). The blue-eyes stereotype: Do eye color, pupil diameter, and scleral color affect attractiveness? Aesthetic Plastic Surgery, 36, 234-240. https://doi.org/10.1007/s00266-011-9793-X

Gutiérrez-García, A., Fernández-Martín, A., Del Líbano, M., \& Calvo, M. G. (2019). Selective gaze direction and interpretation of facial expressions in social anxiety. Personality and Individual Differences, 147, 297-305. https://doi.org/10.1016/j.paid. 2019.04.034

Heijkoop, M., Dubas, J. S., \& van Aken, M. A. G. (2009). Parent-child resemblance and kin investment: Physical resemblance or personality similarity? European Journal of Developmental Psychology, 6, 64-69. https://doi.org/10.1080/17405620802642306

Jablonski, N. G. (2018) Eye color. In W. Trevathan (Ed.), The international encyclopedia of biological anthropology (pp. 1-2). John Wiley \& Sons. https://doi.org/10.1002/ 9781118584538.ieba0541

Kagan, J., \& Snidman, N. (2004). The long shadow of temperament. Belknap Press.

Kardum, I., Gračanin, A., \& Hudek-Knežević, J. (2006). Odnos crta ličnosti i stilova privrženosti s različitim aspektima seksualnosti kod žena i muškaraca [Relations of personality traits and attachment styles with different aspects of sexuality in men and women]. Psihologijske teme 15, 101-128.

Kendrick K. M., Hinton, R. M., \& Atkins, K. (1999). Mothers determine sexual preferences. Nature, 395, 229-230. https://doi.org/10.1038/26129

Kleisner, K., Kocnar, T., Rubesova, A., \& Flegr, J. (2010). Eye color predicts but does not directly influence perceived dominance in men. Personality and Individual Differences, 49, 59-64. https://doi.org/10.1016/j.paid.2010.03.011

Kleisner, K., Priplatova, L., Frost, P., \& Flegr, J. (2013). Trustworthy-looking face meets brown eyes. PLoS ONE, 8(1), e53285. https://doi.org/10.1371/journal.pone.0053285

Laeng, B., Mathisen, R., \& Johnsen, J-A. (2007). Why do blue-eyed men prefer women with the same eye color? Behavioral Ecology and Sociobiology, 61, 371-384. https://doi.org/ 10.1007/s00265-006-0266-1

Laumann, E. O., Gagnon, J. H., Michael, R. T., \& Michaels, S. (1994). The social organization of sexuality. University of Chicago Press.

Luo, S. (2017). Assortative mating and couple similarity: Patterns, mechanisms, and consequences. Social and Personality Psychology Compass, 11, e12337. https://doi.org/ 10.1111/spc3.12337

Matheny, A. P., \& Dolan, A. B. (1975). Changes in eye color during early-childhood: Sex and genetic differences. Annals of Human Biology, 2, 191-196. https://doi.org/10. $1080 / 03014467500000731$

McKusick, V. A. (1966). Mendelian inheritance in man: Catalogs of autosomal dominant, autosomal recessive, and X-linked phenotypes. William Heinemann Medical Books Ltd. https://doi.org/10.1016/B978-1-4831-6679-7.50008-4 
Meier, B. P., Robinson, M. D., Carter, M. S., \& Hinzs, V. B. (2010). Are sociable people more beautiful? A zero-acquaintance analysis of agreeableness, extraversion, and attractiveness. Journal of Research in Personality, 44, 293-296. https://doi.org/10.1016/ j. jrp.2010.02.002

Nojo, S., Tamura, S., \& Ihara, Y. (2012). Human Homogamy in facial characteristics: Does a sexual-imprinting-like mechanism play a role? Human Nature, 23, 323-340. https://doi.org/10.1007/s12110-012-9146-8

Penke, L., \& Asendorpf, J. B. (2008). Beyond global sociosexual orientations: A more differentiated look at sociosexuality and its effects on courtship and romantic relationships. Journal of Personality and Social Psychology, 95, 1113-1135. https://doi.org/10.1037/0022-3514.95.5.1113

Penke, L., \& Denissen, J. J. A. (2008). Sex differences and lifestyle-dependent shifts in the attunement of self-esteem to self-perceived mate value: Hints to an adaptive mechanism? Journal of Research in Personality, 42, 1123-1129. https://doi.org/10. 1016/j.jrp.2008.02.003

Prokop, P., Obertová, Z., \& Fedor. P. (2010). Paternity cues and mating opportunities: What makes fathers good? Acta Ethologica, 13, 101-107. https://doi.org/10.1007/s10211010-0079-0

Rosenberg, A., \& Kagan, J. (1987). Iris pigmentation and behavioral inhibition. Developmental Psychobiology, 20, 377-392. https://doi.org/10.1002/dev.420200403

Rosenberg, A., \& Kagan, J. (1989). Physical and physiological correlates of behavioral inhibition. Developmental Psychobiology, 22, 753-770. https://doi.org/10.1002/dev. 420220802

Rushton, J. P. (1985). Differential K theory: The sociobiology of individual and group differences. Personality and Individual Differences, 6, 441-452. https://doi.org/10. 1016/0191-8869(85)90137-0

Schmitt, D. P. (2014). Evaluating evidence of mate preference adaptations: How do we really know what Homo sapiens sapiens really want? In V. A. Weekes-Shackelford, \& T. K. Shackelford (Eds.), Evolutionary perspectives on human sexual psychology and behavior (pp. 3-42). Springer. https://doi.org/10.1007/978-1-4939-0314-6_1

Schmitt, D. P., \& Pilcher, J. J. (2004). Evaluating evidence of psychological adaptation: How do we know one when we see one? Psychological Science, 15, 643-649. https://doi.org/ 10.1111/j.0956-7976.2004.00734.x

Schmitt, D. P., \& Shackelford, T. K. (2008). Big Five traits related to short-term mating: From personality to promiscuity across 46 nations. Evolutionary Psychology, 6, 246-282. https://doi.org/10.1177/147470490800600204

Shackelford, T. K., LeBlanc, G. J., \& Drass E. (2000). Emotional reactions to infidelity. Cognition and Emotion, 14, 643-659. https://doi.org/10.1080/02699930050117657

Simpson, J. A., \& Gangestad, S. W. (1991). Individual differences in sociosexuality: Evidence for convergent and discriminant validity. Journal of Personality and Social Psychology, 60, 870-883. https://doi.org/10.1037/0022-3514.60.6.870 
Slater, A., Von der Schulenburg, C., Brown, E., Badenoch, M., Butterworth, G., Parsons, S., \& Samuels, C. (1998). Newborn infants prefer attractive faces. Infant Behavior \& Development, 21, 345-354. https://doi.org/10.1016/S0163-6383(98)90011-X

Sohn, K. (2016). Men's revealed preferences regarding women's promiscuity. Personality and Individual Differences, 95, 140-146. https://doi.org/10.1016/j.paid.2016.02.041

Stearns, S. (1976). Life-History Tactics: A Review of the Ideas. The Quarterly Review of Biology, 51, 3-47. https://doi.org/10.1086/409052

Strouts, P. H., Brase, G. L., \& Dillon, H. M. (2016). Personality and evolutionary strategies: The relationship between HEXACO traits, mate value, life history strategy and sociosexuality. Personality and Individual Differences, 115, 128-132. https://doi.org/ 10.1016/j.paid.2016.03.047

Sturm, R., \& Frudakis, T. (2004). Eye colour: Portals into pigmentation genes and ancestry. Trends in Genetics, 20, 327-332. https://doi.org/10.1016/j.tig.2004.06.010

Štěrbová, Z., Tureček, P., \& Kleisner, K. (2019). Consistency of mate choice in eye and hair colour: Testing possible mechanisms. Evolution and Human Behavior, 40, 74-81. https://doi.org/10.1016/j.evolhumbehav.2018.08.003

Watson, D., Klohnen, E. C., Casillas, A., Nus Simms, E., Haig, J., \& Berry, D. S. (2004). Match makers and deal breakers: Analyses of assortative mating in newlywed couples. Journal of Personality, 72, 1029-1068. https://doi.org/10.1111/j.0022-3506.2004. 00289.x

Wilde S., Timpson, A., Kirsanow, K., Kaiser, E., Kayser, M., Unterländer, M., Hollfelder, N., Potekhina, I. D., Schier, W., Thomas, M. G., \& Burger, J. (2014). Direct evidence for positive selection of skin, hair, and eye pigmentation in Europeans during the last 5,000 y. PNAS, 111, 4832-4837. https://doi.org/10.1073/pnas.1316513111

Williams, G. C. (1966). Adaptation and natural selection. Princeton University Press.

Youyou, W., Stillwell, D., Schwartz, H. A., \& Kosinski, M. (2017). Birds of a feather do flock together: Behavior-based personality-assessment method reveals personality similarity among couples and friends. Psychological Science, 28, 276-284. https://doi.org/10. 1177/0956797616678187

Zanetti, R., Rosso, S., Martinez, C., Navarro, C., Scraub, S., Sancho-Garnier, H., Franceschi, S., Gafa, L., Perea, E., Tormo, M. J., Laurent, R., Schrameck, C., Cristofolini, M., Tumino, R., \& Wechsler, J. (1996) The multicentre south European study "Helios". I: Skin characteristics and sunburns in basal cell and squamous cell carcinomas of the skin. British Journal of Cancer, 73, 1440-1446. https://doi.org/10.1038/bjc.1996.274 